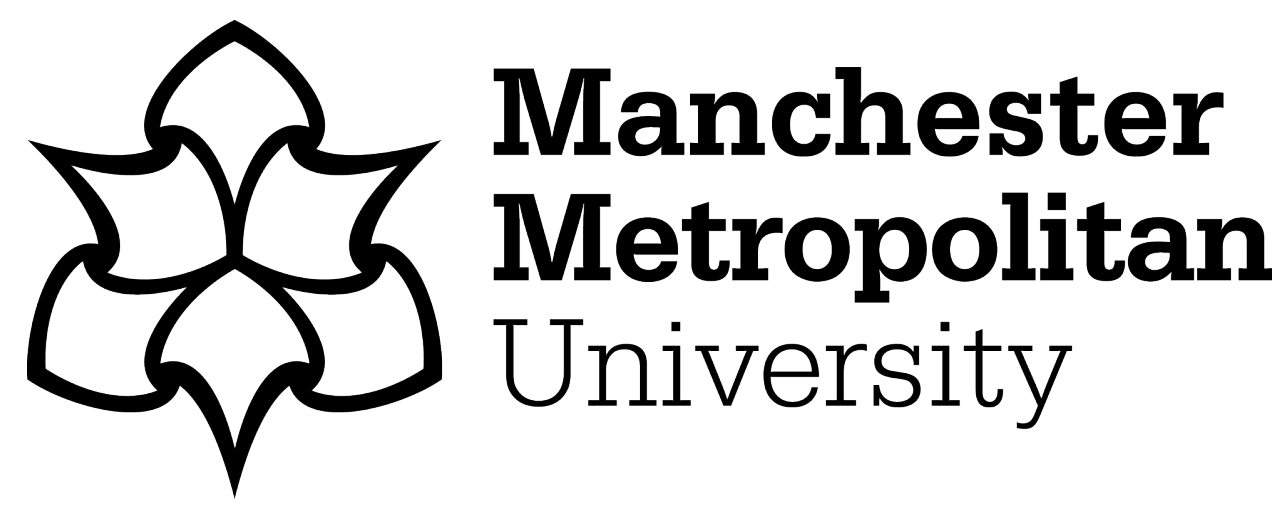

Gray, PM and Ralphs, R (2019) Confidentiality and cultural competence? The realities of engaging young British Pakistanis and Bangladeshis into substance use services. Drugs: Education, Prevention, and Policy, 26 (2). pp. 133-139. ISSN 0968-7637

Downloaded from: https://e-space.mmu.ac.uk/619381/

Version: Accepted Version

Publisher: Taylor \& Francis

DOI: https://doi.org/10.1080/09687637.2017.1398714

Please cite the published version 


\title{
Confidentiality and cultural competence? The realities of engaging young British Pakistanis and Bangladeshis into substance use services
}

\author{
Paul Gray and Rob Ralphs \\ Manchester Metropolitan University, UK
}

\begin{abstract}
This paper focusses on the reasons for the under-representation of British South Asians in substance use services. Based on a small-scale evaluation of a substance use service that delivers targeted outreach support within two predominantly Pakistani and Bangladeshi communities in the north west of England, this paper contributes to the debate around how substance use services can best engage with young British Pakistani and Bangladeshi substance users. The paper highlights the importance of what Fountain (2009) terms low threshold/open access services. Alongside this, the paper argues that the building of trust and confidence in a substance use service are key when it comes to engaging with young Pakistani and Bangladeshi substance users. Yet this necessary process takes time: something that is at odds with the current trend towards short-term funding regimes and 'quick wins'. The paper concludes by advocating the need for, not only a diverse range of engagement strategies, but also a longer-term approach when it comes to developing and delivering substance use services aimed at successfully engaging with this particular group of substance users.
\end{abstract}

\section{Key words}

Substance use, South Asian, cultural competence, targeted outreach

\section{Introduction}

There has been a longstanding acknowledgement in Britain that many ethnic minorities are under-represented in substance use services (ACMD, 1998; Awiah et al., 1990; Buchess \& Morris, 1990; Patel, 2000a), with some Asian communities particularly under-represented as recipients of drugs information, advice and treatment (Beynon et al., 2008; Fountain, 2009; Winters \& Patel, 2003). Indeed the common perception is that the Asian community in Britain is difficult to engage into substance use services (Fountain et al., 2007; Winters \& Patel, 2003).

Between 2000 and 2006, the Department of Health's Black and Minority Ethnic Drug Misuse Needs Assessment Project supported 179 community organisations to conduct needs assessments (see Fountain et al., 2007; Winters \& Patel, 2003). Fountain (2009) collated the findings from 65 local needs assessments on the issues surrounding substance use and substance use services among England's South Asian (Bangladeshi, Indian, Pakistani, and Sri Lankan) communities. In total, 10,485 members of these communities provided the data for the 65 assessments. The overall picture painted by Fountain (2009) is that South Asian communities are struggling to deal with substance use without sufficient knowledge of the issues, within the traditional immediate family support structure, and in isolation from mainstream substance use services. Indeed, a lack of trust in the confidentiality of services appeared to be central when it came to accounting for the under-representation of South Asians in substance use services. As Fountain (2009:6) notes, 'the link between the stigma of drug use and a lack of trust in the confidentiality of drug information, advice and treatment services ... cannot be over-emphasised as a barrier to their access by South Asians'. Indeed for many, the 'social risks' of disclosing one's substance use are seen as more significant than any personal health risks associated with the substance use (Fountain, 2009:27). 
The problem of the under-representation of South Asians in substance use services is exacerbated by the fact that 'the majority of the drug users who had accessed mainstream drug treatment services rated them poorly ... because of the perceived lack of cultural competence in the services' (Fountain, 2009:5). As Fountain (2009:28) points out, despite 'cultural competence' being increasingly used within the public sector, 'there is little agreement over what it means and how it can be implemented'. Indeed, culturally competent services can be developed in 'quite diverse ways depending on the local context' (Bhui et al., 2007:14). Notwithstanding this, Fountain (2009:28) defines culturally competent services as those that incorporate both individual and organisational competence; where individual competence is 'skills-based and relates to an individual practitioners' professional practice in working with diverse communities', and organisational competence is defined by the 'level of maturity in the organisation for addressing equality and diversity across the full range of its functions and policies'. Bearing in mind the particular focus and scale of Fountain's (2009) study, it was felt that her definition of cultural competence was the one most applicable to the specific aims of this paper. As such, her definition is adopted throughout the remainder of this paper.

Notwithstanding the issues identified above - a lack of trust in the confidentiality of substance use services, alongside a perceived lack of cultural competence exhibited by such services substance use amongst young people from South Asian backgrounds has been identified as a 'rising problem' (Patel \& Wibberley 2002:55). The general perception from the 65 reports collated by Fountain (2009:5) is that substance use among young South Asians is 'increasing'. Indeed, Pearson and Patel (1998) argued that some ethnic minority groups are catching up with their White counterparts in terms of their substance use. For example, several school-based self-report surveys (see Best et al., 2006; Jayakody et al., 2006; Rodham et al., 2005) have reported that, notwithstanding some slight differences in the patterns and prevalence of drug and alcohol use, substance use among young British Asians differs little from that of the general population. With this in mind, it is clear that the lower levels of engagement of young South Asian substance users into substance use services is an issue that warrants attention.

Despite a focus on young people (see Bashford et al., 2001; Bola \& Walpole, 1997; Patel \& Wibberley, 2002), much research to date on substance use within South Asian communities has discussed these communities more generally. In this paper, we focus the lens explicitly on the engagement into substance use services of young people from two specific South Asian communities; namely the Pakistani and Bangladeshi communities. According to census data, Asian/Asian British residents represent the second largest group after the White/White British population (ONS, 2012). The most common Asian nationalities within this broad category are Indian, Pakistani and Bangladeshi with recent increases being greatest in Pakistani and Bangladeshi communities (Jivraj, 2012; ONS, 2012). In addition, these groups have high proportions of young people compared to the White/White British population (Centre for Policy and Ageing, 2013; ONS, 2013); a statistic that gains added relevance when we consider that higher rates of substance use are associated with young people (see Aldridge et al., 2011; Home Office, 2016). Furthermore, these groups tend to live in some of the most deprived neighbourhoods afflicted by poor housing, inadequate education, limited access to health services, low income and unemployment (Jivraj \& Khan, 2013); factors consistent with some types of substance use (Pearson \& Patel, 1998).

This paper reports the findings from a small-scale evaluation commissioned by a substance use service - referred to under the pseudonym Making a Difference - in the north west of England. Making a Difference has been delivering young people's drug and alcohol services in the area since the early 1990s, and supports young people up to the age 21 years old. The evaluation 
was commissioned to focus on one particular aspect of the service; a targeted outreach programme aimed specifically at improving engagement with young substance users in two predominantly Pakistani and Bangladeshi communities within the service's largely ethnically White catchment area. Many commentators have stressed that outreach work is necessary to access black and minority ethnic substance users and those at risk of substance use (see Hothi \& Belton, 1999; Patel, 1997; Pearson \& Patel, 1998). The targeted outreach programme delivered by Making a Difference was developed in 2009 in response to the very low number of referrals from the Pakistani and Bangladeshi communities in question: only four per cent of all referrals to Making a Difference in 2009 were Pakistani or Bangladeshi. This low percentage reflected a considerable under-representation of the youth population in the two communities. The proportion of Pakistani or Bangladeshi young people ranged from 75 per cent in one of the communities to 82 per cent in the other (ONS, 2013). Given the ethnic composition of the communities, along with the levels of substance use amongst young South Asians outlined above, it was imperative that Making a Difference increased the number of referrals into the service from these two communities.

In terms of the targeted outreach programme itself, an outreach team provided a visible and consistent presence on the streets in the two communities, with outreach workers walking the streets two evenings a week. The street-based outreach work was complemented by outreach work in the local educational establishments whereby members of the outreach team provided a regular pattern of visits to the local high schools and colleges. At the time of the evaluation, the targeted programme outlined above had led to an increase in Pakistani and Bangladeshi referrals to the service from only four per cent of all referrals in 2009 to 36 per cent in June 2014. How Making a Difference achieved this increase in engagement amongst a group that has traditionally been found to be hard to engage into substance use services (see Fountain 2009) was the evaluation's primary research question and is the focus of this paper.

\section{Methodology}

The evaluation of the Making a Difference service took place during 2015 and comprised a number of strands. Firstly, interviews were conducted with six Make a Difference staff and 18 young Pakistanis and Bangladeshis who were actively engaging with the service at the time. In addition, 18 interviews were conducted with a range of stakeholders and partner agencies in the area, including: youth offending teams; schools and colleges; social work and health care agencies; youth and community agencies; and other substance use services. In total, 42 interviews were undertaken. All the interviews were fully transcribed and analysed using NVivo, a qualitative analysis software package. Alongside these interviews, a detailed ethnographic observation of the service was conducted. This included accompanying the outreach team during their street-based outreach work, and also observing the service's outreach work in local schools and colleges. The final strand of the research was an analysis of existing quantitative monitoring data routinely collected by the service. The monitoring data provided to the research team covered a period of two years: from the $1^{\text {st }}$ November 2011 to the $31^{\text {st }}$ October 2013. The data was very limited and covered only basic demographic information, referral source and primary problem at referral. It is important to mention that, for the purposes of the evaluation, this data was used to simply provide a picture of the young people the service engaged with, rather than to investigate any 'impact' that the service may or may not have had. The analysis of the service's monitoring data was undertaken using IBMSPSS, a quantitative software analysis package. 


\section{The extent of substance use}

Before moving on to look at the issues of lack of trust in the confidentiality of substance use services along with the perceived lack of cultural competence exhibited by such services, it is worth firstly highlighting the nature of the substance use disclosed by the young people engaged with Making a Difference. On referral to the service, the young people are asked whether they have a problem with drugs, alcohol, or drugs and alcohol. Analysis of the service's monitoring data showed that, in the two years between November 2011 and October 2013 , nearly nine tenths of the Pakistani and Bangladeshi referrals $(n=70)$ disclosed a problem with just drugs (unfortunately the data did not specify which drugs) when they started working with the service, compared to around half $(n=352)$ of the White participants. In contrast, only two of the Pakistani and Bangladeshi participants disclosed a problem with just alcohol, as compared to nearly a fifth $(n=124)$ of the White participants. Added to this, only a tenth $(n=8)$ of the Pakistani and Bangladeshi participants disclosed a problem with drugs and alcohol, compared to nearly a third $(\mathrm{n}=210)$ of the White participants. Despite these findings, it was claimed by a number of partner agencies and Making a Difference staff that alcohol use is prevalent among young Pakistanis and Bangladeshis in the communities targeted by the outreach programme. Perhaps the reason for this disparity is a result of alcohol being 'haram' or forbidden under Islam (Bradby 2007). As evidenced below, this could have influenced whether or not a young person chose to disclose their alcohol use at referral.

There's a lot of young Pakistani people who are using alcohol, but the other [White] young people will be more open about their levels of alcohol use. (College student support staff)

Although the forbidden nature of alcohol appeared to be a factor when it came to the young Pakistanis and Bangladeshis disclosing their alcohol use, there seemed to be no such inhibitions when it came to disclosing Cannabis use. Cannabis use by the young Pakistanis and Bangladeshis in the area in which the service works appeared to be widespread (see also Fountain 2009), arguably to the point of normalisation (Parker et al. 1998; Parker et al. 2002; Williams et al. 2016).

What we see with the BME groups that we are working with is heavy Cannabis use. ... These young people haven't got any friends that don't use [Cannabis]. (Making a Difference staff member)

Everyone's smoking [Cannabis], even people younger than me. People older than me, they just supply it. ... It's everywhere, it's increasing. (SU12 15-year old Bangladeshi male)

\section{Increasing trust in the confidentiality of substance use services}

The issue of a lack of trust in the confidentiality of substance use services has been shown to be key when it comes to explaining the under-representation of South Asians in these services. As Fountain (2009:26) points out:

The majority of study participants believed that, in the close community settings in which many South Asians live, nothing can be kept private for very long. ... Therefore, if access to drug services is to be increased, it is essential that community members trust that confidentiality will not be breached.

In all the interviews with the young Pakistani and Bangladeshi service users, when the issue of confidentiality was raised the primary concern was focused on the family. While it was noted by Making a Difference staff and partner agencies alike that young people having concerns 
about their parents/family finding out about their substance use is of course not restricted to young Pakistanis and Bangladeshis, there is a stronger emphasis placed on the notions of shame and family honour within the Pakistani and Bangladeshi community. As Fountain (2009:16) found, 'the stigma attached to the use of drugs ... is also felt among ... the extended family and family friends'.

The most common one [concern for young Pakistanis and Bangladeshis] was about parents finding out. That's always been a worry for them, especially some of the females. ... The biggest stigma is probably parents finding out, more than anything else. (Making a Difference staff member)

There's a lot more pressure [on young Pakistanis and Bangladeshis] in terms of "How will this be seen?" or "Am I seen to be bringing shame?". (Making a Difference staff member)

Notwithstanding the above quotes, when it came to the question of how young Pakistanis and Bangladeshis trust in the confidentiality of Making a Difference impacted upon their engagement, the evaluation found that successful engagement appeared to be dictated less by the issue of confidentiality, and more by the ability of the service to 'gain entry' into the two communities. For example, as evidenced in the quote below, once a young person actually engages with Making a Difference, the issue of confidentiality is promptly addressed - all those who engage with the service are assured at their initial meeting that what they disclose will be kept confidential and not shared with other agencies and/or family members.

I talked to [the outreach worker] and he goes "Yeah, it's fully confidential" so I thought, "yeah, might as well give it a go". ... When I first went [to Making a Difference] I weren't that sure innit, but they told me it was all confidential and that. (SU17 15-year old Pakistani male)

The evaluation found that an important precursor to a young person actually even engaging with the outreach workers appeared to hinge on the ability of the outreach programme to, firstly gain entry into the two communities, and secondly have young people in the communities start to trust in the legitimacy of the outreach workers and ultimately Making a Difference itself. It is highly unlikely that young people in general will openly discuss their substance use with unknown outreach workers. Added to this, the two communities where the service's outreach programme was focused are linked to drug dealing as well as drug use. As such, the arrival of outreach workers into the two communities was understandably met with suspicion.

There's a lot of suspicion we meet. I mean, I've seen a young person ... and he's said, "Do you work for the police?". (Making a Difference staff member)

Yet getting young Pakistanis and Bangladeshis to trust in the legitimacy of the workers and the service did appear to be a key factor in the success of the outreach programme. The ethnographic observations found that any initial suspicion and mistrust of the service that young people in the two communities may have had when the outreach programme first started appeared to have been replaced with high levels of trust in both the outreach workers and the service itself, and this was something that came through strongly in the interviews. Indeed it was acknowledged by Making a Difference staff, partner agencies and the young people themselves that gaining entry into the two communities and building trusting relationships was central to the outreach programme's ability to engage with young Pakistani and Bangladeshi substance users. 
Young people in [this area] can be hostile and you need to take time winning their trust. This is key to the success of [the service]. ... They put the time into being present regularly, forming relationships with young people. (Community worker)

[When we've been doing outreach work] we've had people where we've seen them maybe three, four weeks in a row and then gradually they say "Oi, could you sign us up?" And that's what it takes. ... Very rarely will we get someone who'll say first time round "Yeah, sign me up". (Making a Difference staff member)

It's like you're building trust with them innit. That's why after a couple of months I started slowly sort of trusting them. (SU9 15-year old Pakistani male)

[INT: So you're OK with the worker knowing about your drug use?] Yes, because the worker, I trust him now innit. (SU4 14-year old Pakistani female)

After a while I introduced them [my friends] to him [the outreach worker] and I told them, like my mates, "He's a good guy, I trust him, he won't tell no one". (SU2 15-year old Bangladeshi male)

As can be seen in the above quotes, gaining entry into the two communities took time. This was further evidenced by the fact that during the first year or so the outreach programme generated little in the way of new referrals to the service. Yet, the Making a Difference staff were fully aware that gaining entry into the Pakistani and Bangladeshi communities in which they were working was not something that would happen overnight; particularly when the service in question was a drugs and alcohol service.

It took us a year to establish ourselves within the community. (Making a Difference staff member)

It was after four years when we hit our threshold of the right amount of referrals that we should be getting in. That's how long it took to really embed the service. (Making a Difference staff member)

Making a Difference were fortunate that the funding for the outreach programme was not tied explicitly to the programme achieving particular targets and outcomes; something which, as illustrated in the quote below, may not be possible in the current financial climate.

We were fortunate that it [when the outreach programme started] was at a time when money was abundant. Nowadays, ... if you don't get a result in six months you're screwed, in terms of payments by result or whatever. (Making a Difference staff member)

What also appeared to be important in helping to embed the outreach workers and the service in the two communities it targeted was the ability of the service to maintain a regular and high profile presence in those communities. However, this was only made possible because a strategic decision had been made at the outset of the outreach programme to focus on two small communities local to the service. Staying focused within these small geographical areas meant that the service was better able to establish a regular and consistent presence. As highlighted in the quotes below, this was an important decision that has served the service well. 
When we first started ... we walked around the streets. Basically, every time we were out, we'd walk the same route, got to know the area, got to know the people. (Making a Difference staff member)

Talking to young people that we come across, attending youth clubs, any community events in those areas, ... being a presence on the streets. (Making a Difference staff member)

People from our school, they all know them [the outreach workers]. People at the youth clubs, they all know them as well, and in the community like, surrounding our area, they all know them. (SU6 15-year old Bangladeshi female)

\section{Cultural competence}

As noted in the Introduction, Fountain (2009:5) found that in addition to a lack of trust in the confidentiality of substance use services, 'the majority of the drug users who had accessed mainstream drug treatment services rated them poorly ... because of the perceived lack of cultural competence in the services'. Two recommendations that Fountain makes to improve the cultural competence of substance use services working within South Asian communities is to firstly employ more South Asian workers, and secondly, to provide more 'low threshold/open access services' (Fountain 2009:30). Each of these recommendations will now be looked at in turn in relation to the development and delivery of Making a Difference's targeted outreach programme.

\section{The employment of South Asian workers}

Fountain (2009:26) found that the 'majority' of the 65 needs assessments she looked at 'wanted more South Asian drug workers because of their understanding of the South Asian culture'. The common perception being that this will increase levels of service user engagement within those communities.

There's this thing about "they won't engage with you because you're not Asian, you need to be Asian". (Making a Difference staff member)

Yet as Fountain (2009:30) goes on to point out, 'staffing is a more complex issue than simply employing workers who are from the same ethnic group as potential clients'. For example, the evaluation found that when it came to engaging young Pakistanis and Bangladeshis into the service, being from the same ethnic background as the young people appeared to (initially at least) hinder one of the outreach worker's ability to successfully engage with the young people.

When we first started, there was some [Pakistani and Bangladeshi] young people who weren't open to me, and [yet] they were more open to [the White outreach worker]. They thought "Oh, this guy might know my brother or my sister or my cousin”. (Pakistani Making a Difference staff member)

Despite concerns that workers from the same ethnic background as the young people could compromise confidentiality, as Fountain (2009:30) points out, having an ethnically diverse team does demonstrate organisational cultural competence and communicate an implicit message that they [the service] can respond to the needs of the whole population'. Nonetheless, what appeared to be more important than the ethnic make-up of the service was the individual cultural competence of the workers themselves. It is pertinent to note here that, apart from a single Pakistani outreach worker, the remainder of the Making a Difference workers were all 
White. Yet, as highlighted in the quotes below, ethnicity was no barrier to the workers' ability to engage with the young people.

It's the way he [the White outreach worker] explained it. He explained it to me like on my level, so I'd understand what he was saying. (SU 9 15-year old Bangladeshi male)

He [the White outreach worker] has a technique that no one else has got. [INT: In what way? Can you give me any examples?] Like, he'll get to you, like, explain to you, like, put you in a situation that you've already been in, or he's already been in, and then you know what he's on about. (SU12 15-year old Bangladeshi male)

He [the White outreach worker] doesn't judge you, he gives you, like, help in a good way, not in a bad way, like, he talks to you on the level. (SU1 14-year old Pakistani female)

\section{Low threshold/open access services}

Discourse around the traditionally low levels of South Asian communities' engagement with substance use services has centred upon the stigma or shame associated with attending community-based services (Fountain 2009). To this end, the service's decision to undertake outreach work in local schools and colleges, alongside more traditional street-based outreach work, was cited as a key strategic move by both Making a Difference staff and partner agencies.

Engaging people within school is a safe place to do it. ... It's a clever place to be. (Adult service provider)

It's great. You get that captive audience in a school, and maybe for them, it's that space where they can come and see the drug worker. ... It's not as intrusive as a drug worker knocking on the door every week. (Making a Difference staff member)

In school it's so easy, isn't it? ... Even though they are Bangladeshi and Pakistani, that stigma is gone. (School-based health care worker)

With specific reference to Pakistani and Bangladeshi college students, the point was made that for some, attending college provides them with an alibi and hence the space to seek support that they would otherwise be unable to access.

It's that rigid, sometimes, that college is the only thing some of them [Pakistani and Bangladeshi students] are allowed to come to. And it's a difficult one really, they may say "If my parent rings up, say we all had to stay late" that sort of thing. (College student support staff)

As well as affording a heightened sense of confidentiality, it was noted that if a young person had to travel to the Making a Difference premises, there would in all likelihood be a significant decrease in completed appointments.

If you were to say to the majority of these children "Right, you've to go into [the town centre] to this address", ... I think you'd lose 50 per cent straight away. (School-based healthcare worker)

Having a dual presence on the streets and in the places where young people study clearly afforded the Making a Difference staff the opportunity to connect with young people in a different environment. This was particularly important in relation to engaging with young 
Pakistani and Bangladeshi females. Engaging with young Asian female substance users is often cited (see Fountain 2009) as a challenge for substance use services. It was noted during the interviews with Making a Difference staff and partner agencies that females are less visible on the streets than their male peers, and as a result, are less likely to benefit from more traditional street-based outreach work. With this in mind, the ability of the service's work in the local schools and colleges to engage with young Pakistani and Bangladeshi females is significant. Indeed, analysis of the service's monitoring data showed that, of the 12 Pakistani and Bangladeshi females who engaged with the service between November 2011 and October 2013 , over three quarters $(n=10)$ were referred from the local schools and colleges.

When we have been out on the street-based work ... the vast majority [of Pakistanis and Bangladeshis we are coming into contact with] are young males. But then the second strand of work has been a lot of focused outreach in the schools, ... and we are seeing young females start to access the support through the schools. (Making a Difference staff member)

In addition to the outreach work in schools and colleges, Making a Difference also has a very active social media presence. Bearing in mind the sensitivity that exists amongst many young Pakistanis and Bangladeshis when it comes to accessing substance use services (see Khan \& Ditton, 1999), being able to easily access information through social media was highlighted as particularly valuable for this group of young people. As this member of a college's student support staff highlighted, for some young Pakistanis and Bangladeshis, even being in possession of information leaflets was deemed inappropriate.

Often they [young Pakistanis and Bangladeshis] will talk to people [from the service] but they won't take written information or leaflets. They can't take that home. (College student support staff)

The service has established a good reputation for their social media presence with a regularly updated website, twitter account and Facebook page. The above comment illustrates the value in having a diverse model of information sharing and advice whilst simultaneously highlighting the culturally specific challenges presented by outreach work in South Asian communities. Furthermore, Making a Difference's social media presence was also highlighted as a model of good practice in the way that it makes information around substance use accessible for both professionals and young people seeking advice around substance use.

The website is really young people friendly, so we can bring it up and say "This is what [the service] can offer, this is what they do." So that's been positive, really very positive. (College student support staff)

They [the service] are pretty on the ball. ... Really great with social media and things that are really attractive for young people. I know because when I'm on Twitter, things are coming through all the time, even at weekends. ... And they [the service] are quite brave and courageous with what they send out, which I think is positive. (Adult service manager)

\section{Conclusion}

As can be seen, when it comes to the question of how to successfully engage with young Pakistani and Bangladeshi substance users, the ability of a service to deliver a diverse range of engagement strategies appears to be key. For example, one of the most successful methods of engagement adopted by Making a Difference was the low threshold/open access service in the form of outreach work in schools and colleges. Whereas a central tenet of more traditional 
outreach work involves maintaining a visible presence on the streets, when it comes to engaging with young Pakistani and Bangladeshi substance users, this alone is not sufficient. This is particularly the case when it comes to engaging with young Pakistani and Bangladeshi females. What was central to the success of the targeted outreach programme (in terms of increased referrals from young Pakistanis and Bangladeshis) was the fact that Making a Difference was able to provide traditional street-based outreach and outreach work in educational establishments; with both supplemented/complemented by an active social media presence.

Notwithstanding this, services need to be aware that simply delivering a diverse range of engagement strategies on its own is unlikely to result in increased engagement. What is crucial is that services ensure that they are fully embedded into the communities they wish to engage with. For it is not until the group being targeted trust in the legitimacy of a service and its employees that they will engage with the service, irrespective of the engagement strategies adopted. However, as previously discussed, the process of embedding the Making a Difference service into the two communities in which the targeted outreach programme was delivered took several years to come to fruition. This is in line with research that has found that engaging with substance users in South Asian communities does require a longer-term approach (see Patel 2000a, 2000b; Ram 2000). Indeed, as Fountain (2009:6) noted, it 'requires sensitivity, persistence, time, and meaningful engagement with communities'. Yet in the current climate of short-term funding, targets and KPIs, it is increasingly challenging for substance use services like Making a Difference to persist with a model of working that is not immediately producing results (in terms of referrals through the door). It is therefore essential that funders and commissioners are mindful of the time it takes for substance use services to gain entry into communities, particularly those South Asian communities that have traditionally been found to be hard to engage into substance use services (Fountain 2009). Related to this is the issue of substance use services being pressured by funders and commissioners into spreading themselves too 'thinly' to maximize any impact they might have as widely as possible. As stated earlier, a central factor in Making a Difference's ability to embed itself in the two communities it targeted was the fact that the (relatively small) outreach team was able to maintain a visible and consistent presence in the communities. It was clear that the strategic decision to focus the service in two relatively small geographical areas, rather than more widely across the whole catchment area, was key to the service being able to successfully engage with the young Pakistani and Bangladeshi substance users in those areas. Again, this is something that funders and commissioners need to be conscious of.

Patel and Wibberley (2002: 57) end their paper by noting that some concrete examples of good practice would have provided a suitable conclusion, but unfortunately they were not able to find any such examples. As a result, they concluded that they 'would welcome ... examples of good practice in working with ethnic minority children in relation to substance (mis)use'. While it was unfortunate that the evaluation on which this paper is based was not able to comment on the impact of Making a Difference (in terms of outcomes), the findings presented in this paper would suggest that when it comes to engaging with young Pakistani and Bangladeshi substance users, Making a Difference's targeted outreach programme might be one such example of good practice.

\section{References}

Aldridge, J., Measham, F., \& Williams, L. (2011). Illegal Leisure Revisited: Changing Patterns of Alcohol and Drug Use in Adolescents and Young Adults. London: Routledge. 
ACMD. (1998). Drug misuse and the environment. London: The Stationery Office.

Awiah, J., Butt, S., \& Dorn, N. (1990). 'The last place I would go': Black people and drug services in Britain. Druglink, 5(5), 14-15.

Bashford, J., Patel, K., Sheikh, N., \& Winters, M. (2001). A review of current drug service provision for the South Asian community in Calderdale, with a particular focus on young people. Report to Healthy Living Team (February 2001). Preston: Centre for Ethnicity and Health, University of Central Lancashire.

Best, D., Manning, V., Gossop, M., Gross, S., \& Strang, J. (2006). Excessive drinking and other problem behaviours among 14-16 year old schoolchildren. Addictive Behaviors, 31(8), 1424-1435.

Beynon, C.M., McMinn, A.M., \& Marr, A.J.E. (2008). Factors predicting drop out from, and retention in, specialist drug treatment services: A case control study in the North West of England. BMC Public Health, 8(149), 1-11.

Bhui, K., Warfa, N., Edonya, P., McKenzie, K., \& Bhugra, D. (2007). Cultural competence in mental health care: a review of model evaluations. BMC Health Services Research, $7(1)$.

Bola, M. \& Walpole, T. (1997). Drugs information and communication needs amongst South Asian 11-14 year old boys. London: Home Office North West London Drugs Prevention Team.

Bradby, H. (2007). Watch out for the Aunties! Young British Asians' accounts of identity and substance use. Sociology of Health \& Illness, 29(5), 656-672.

Burchess, I. \& Morris, C. (2009). Access, Barriers and Facilitators to Drug Treatment Programmes in Wolverhampton: A Review of the Literature. Journal of Health and Social Care Improvement, May Issue, 1-6.

Centre for Policy on Ageing. (2013). The ageing of the ethnic minority populations of England and Wales: Findings from the 2011 census. Retrieved from:

http://www.cpa.org.uk/information/reviews/theageingoftheethnicminoritypopulations ofenglandandwales-findingsfromthe2011 census.pdf

Fountain, J., Patel, K., \& Buffin, J. (2007). Community engagement: The Centre for Ethnicity and Health model. In D. Domenig, J. Fountain, E. Schatz, \& G. Broring (Eds.), Overcoming barriers: migration, marginalisation and access to health services. Amsterdam: AMOC.

Fountain, J. (2009). Issues surrounding drug use and drug services among South Asian communities in England. Preston: University of Central Lancashire.

Home Office. (2016). Drug Misuse: Findings from the 2015/16 Crime Survey for England and Wales. Statistical Bulletin 07/16. London: Home Office.

Hothi, A. \& Belton, E. (1999). Use of drug services in Buckinghamshire by Asian Class A drug users aged 16-25. Aylesbury: Buckinghamshire Drug Action Team.

Jayakody, A.A., Viner, R.M., Haines, M.M., Bhui, K.S., Head, J.A., Taylor, S.J.C., \& Stansfeld, S.A. (2005). Illicit and traditional drug use among ethnic minority adolescents in East London. Public Health, 120(4), 329-338.

Jivraj, S. (2012). How has ethnic diversity grown 1991-2001-2011? Manchester: Centre on Dynamics of Ethnicity.

Jivraj, S. \& Khan, O. (2013). Ethnicity and deprivation in England: How likely are ethnic minorities to live in deprived neighbourhoods? Manchester: Centre on Dynamics of Ethnicity.

Khan, F. \& Ditton, J. (1999). Minority ethnic drug use in Glasgow. Part two: special problems experienced and possible gaps in service provision. Glasgow: Glasgow Drugs Prevention Team.

ONS. (2012). Detailed Characteristics for England and Wales, March 2011. London: ONS. 
ONS. (2013). Detailed Characteristics for England and Wales, March 2012. London: ONS.

Parker, H., Aldridge, J., \& Measham, F. (1998). Illegal Leisure: The Normalization of Adolescent Recreational Drug Use. London: Routledge.

Parker, H., Williams, L., \& Aldridge, J. (2002). The Normalization of 'Sensible' Recreational Drug Use: Further Evidence from the North West England Longitudinal Study. Sociology, 36(4), 941-964.

Patel, K. (1997). A local and national perspective on Asian drug and alcohol use. In NWLHPU/GMLCA: Alcohol and drugs: a transcultural perspective. Conference report. Manchester: North West Lancashire Health Promotion Unit/Greater Manchester and Lancashire Council on Alcohol.

Patel, K. (2000a). Minority ethnic drug use: the missing minorities.' In F. Harbin \& J. Murphy-Russell (Eds), Substance Misuse Its Effects on Families and Child Protection. Lyme Regis: Russell House.

Patel, K. (2000b). Using qualitative research to examine the nature of drug use among minority ethnic communities in the UK. In J. Fountain (Ed.), Understanding and responding to drug use: the role of qualitative research. European Monitoring Centre for Drugs and Drug Addiction Scientific Monograph series. Lisbon: EMCDDA.

Patel, K. \& Wibberley, C. (2002). Young Asians and Drug Use. Journal of Child Health Care, 6(1), 51-59.

Pearson, G. \& Patel, K. (1998). Drugs, Deprivation, and Ethnicity: Outreach among Asian Drug Users in a Northern English City. Journal of Drug Issues, 28(1), 199-224.

Ram, H. (2000). Asian communities project report to National Lottery Charities Board. Dudley: The Warehouse (Dudley Drug Project).

Rodham, K., Hawton, K., Evans, E., \& Weatherall, R. (2005). Ethnic and gender differences in drinking, smoking and drug taking among adolescents in England: a self-report school-based survey of 15 and 16 year olds'. Journal of Adolescence, 28(1), 63-73.

Williams, L., Ralphs, R., \& Gray, P. (2016). The Normalisation of Cannabis Use Among Bangladeshi and Pakistani Youth: A New Frontier for the Normalisation Thesis?. Substance Use and Misuse, 52(4), 413-421.

Winters, M. \& Patel, K. (2003). The Department of Health's Black and minority ethnic drug misuse needs assessment project. Preston: University of Central Lancashire. 